\title{
Self report functional disability scores and the use of devices: two distinct aspects of physical function in rheumatoid arthritis
}

\author{
A van der Heide, J W G Jacobs, G A van Albada-Kuipers, F W Kraaimaat, R Geenen, \\ J W J Bijlsma
}

\begin{abstract}
Objectives-Self report scores of physical disability and the use of devices or assistance in performing activities are sometimes integrated in one index of physical function, although they are aimed at measuring different dimensions of physical disability. The properties of both parameters were evaluated in two groups of patients with rheumatoid arthritis (RA).
\end{abstract}

Methods-A group of patients with RA of recent onset was compared with a group with established disease on four parameters of disability: use of devices, use of personal assistance, and scores on a validated Dutch version of the Health Assessment Questionnaire Disability Index, with and without integrating the use of devices or assistance. Correlation coefficients among disability parameters were calculated. In multiple regression analysis the influence of disease duration on the disability parameters was determined after disease activity, psychological wellbeing, and demographical characteristics had been controlled.

Results-Functional disability scores were mainly related to inflammatory activity and psychological wellbeing, whereas the use of devices had a strong relation with disease duration, independent of current disease activity. Integrating these parameters of disability yielded a parameter that was still mainly associated with disease activity.

Conclusion-Self report scores of functional disability and the use of devices represent distinct dimensions of physical function in RA. Integrating both parameters into one measure of physical disability does not provide an index adequately reflecting both dimensions. The use of both parameters to measure outcome in long term clinical studies is recommended.

(Ann Rheum Dis 1993; 52: 497-502)

In studies on the course of rheumatoid arthritis (RA) or the effectiveness of various treatment modalities, functional status is an important outcome measure. Traditional measures such as joint count, grip strength, and erythrocyte sedimentation rate do not describe sufficiently the impact of RA on patients' daily life. Self report questionnaires, such as the Stanford Health Assessment Questionnaire (HAQ) and the Arthritis Impact Measurement Scales and its revised version, have been developed to get a more comprehensive idea of patients' daily life and functioning. ${ }^{1-3}$

In several studies the validity of these self report questionnaires has been established. Reports of patients have been shown to correspond highly with clinical observations of physiotherapists or occupational therapists, which is an indication that self report scores reflect the actual functional abilities. ${ }^{4-7}$ Correlations between self report scores of functional disability and traditional measures of disease activity are usually moderately strong, ${ }^{8-12}$ and sensitivity to change in clinical trials has been shown to be good. ${ }^{13}$

In the long term, functional disability will be affected not only by current inflammatory activity but also by structural damage to the joints. The degree to which self report scores reflect either of these factors has not been clearly established. Pincus et al found that radiographic scores correlated significantly with functional disability scores. ${ }^{8}$ In other studies no correlations between radiographic stages of structural joint damage and functional health status were found. ${ }^{14}$ The relation between disease duration and self report scores of disability is also not clear. Some studies have shown a deterioration in disability over a number of years, ${ }^{16}{ }^{17}$ whereas others have found functional status to be constant over a longer period of time..$^{18} 19$

The degree to which patients learn to adapt to their physical impairments in the course of the disease-for example, by using auxiliary devices, may affect self report scores of functional status, and correlations with disease duration and indices of structural joint damage. Some questionnaires on physical function, such as the HAQ disability index, incorporate in their overall score the use of devices or assistance from other people in performing activities, ${ }^{1}{ }^{20}$ but others do not. ${ }^{2}$ The items from the HAQ, however, are focused on the degree of difficulty, due to current disease activity and pain, that patients experience in performing daily life activities, whereas the use of devices or assistance reflects the degree of dependence, which is likely to be affected mainly by enduring damage and 
coping behaviour. The validity of integrating these two different dimensions in one disability measure has never been investigated. The aim of this cross sectional study was to gain insight into the properties of self report scores of functional status, the use of devices, and the use of assistance as disability parameters. The results are described of a comparison of disability parameters between patients with RA of recent onset and patients with established disease.

\section{Patients and methods}

Two groups of patients with a diagnosis of RA according to the revised criteria of the American College of Rheumatology of 1987 were studied. ${ }^{21}$ The first group consisted of 97 consecutive recently diagnosed outpatients who were to be enrolled in a prospective trial comparing the effectiveness of several drug treatment strategies. To be included, the duration of disease had to be less than one year. The second group included 100 patients who had had RA for more than one year and who had volunteered to take part in a study on behavioural and occupational treatment modalities. Results of this study have been described elsewhere. ${ }^{22}$ The mean duration of disease in this group was 14.9 years (SD 11.7, range 2-59). In both groups patients were older than 18 years. The mean (SD) age in the group with disease of recent onset was 55.6 $(15 \cdot 1)$ years; in the group with established disease it was $58.3(12.6)$ years. The percentages of women were 67 and 68, respectively. Patients were free from any serious associated disease. They came from four clinical centres in the region of Utrecht, The Netherlands. The measurements reported here were done at the start of the trial in both groups.

\section{FUNCTIONAL STATUS ASSESSMENT}

The questionnaire used to assess functional status (questionnaire daily functioning, or vragenlijst dagelijks functioneren) is a validated Dutch version of the HAQ disability index. ${ }^{7}$ It contains 20 items, which are grouped into eight scales representing dressing, arising, eating, walking, hygiene, reach, grip, and outside activity. Patients are asked about the ability to perform activities without help, with responses 'able to do without difficulty' (score zero), 'able to do with some difficulty' (score one), 'able to do with much difficulty' (score two), and 'unable to do' (score three). Furthermore, patients are asked whether or not they use a cane, a wheelchair, an adapted bed or chair, or devices for dressing, hygiene, or eating, and whether or not they are assisted in performing any of the activities of the eight scales.

Two different overall functional disability scores were calculated. For the first score the average of the highest scores on each scale was taken. For the second score the use of devices or assistance was integrated in the functional disability score. This integrated score was calculated by averaging the highest scores on each scale, taking a score of at least two for a scale when a device or help from another person is used in performing any of the activities of that scale. This integrated score is similar to the HAQ disability index which is frequently applied. ${ }^{1}$ Both overall scores vary from zero to three, zero being the best (no problems) and three being the worst possible score. The groups were compared on four functional disability parameters: the use of devices, the use of assistance, the overall functional disability score, and the integrated overall disability score.

\section{OTHER ASSESSMENTS}

The measurement of disease activity included a joint score according to the method described by Thompson (simultaneous presence of joint tenderness and swelling; the score is weighted for joint size; range $0-534),{ }^{23}$ duration of early morning stiffness in minutes (maximum 720), and pain. To assess pain a Dutch version of the pain scale of the Arthritis Impact Measurement Scale was used. ${ }^{10}$ Laboratory parameters were the erythrocyte sedimentation rate (Westergren method, $\mathrm{mm} / 1 \mathrm{st} \mathrm{h}$ ), haemoglobin concentration $(\mathrm{g} / \mathrm{l})$, and platelet count $\left(\times 10^{9} / 1\right)$.

Psychological wellbeing was assessed with a validated arthritis-specific questionnaire, containing scales on physical, psychological, and social aspects of quality of life (impact of rheumatic diseases on health and lifestyle, invloed van reuma op gezondheid en leefwijze). ${ }^{10}$ The scores on three psychological wellbeing scales were used in this study: depressive mood, cheerful mood, and anxiety. These scales are derived from Dutch instruments previously found to be reliable and valid (ref 24 and Zwart F, Spooren J, unpublished data).

\section{STATISTICAL ANALYSIS}

Because of the skewness of the distributions of some variables their values were transformed. Square root transformation yielded satisfying distributions (skewness less than 1.0 ) for the variables joint score, morning stiffness, erythrocyte sedimentation rate, platelets, depressive mood, and anxiety. The statistical significance of differences between the groups was tested with Student's $t$ test. Both study groups were combined for correlation and regression analysis. Because of the relative overrepresentation of patients with a short disease duration, a random sample of 40 patients was taken from the group with disease of recent onset, resulting in a sample size of 140 for the combined group. Bivariate relations between disability parameters were analysed for the combined group by calculating Pearson's correlation coefficients. Hierarchical multiple regression analysis was used to determine the influence of disease duration on disability parameters. Disease activity parameters, psychological wellbeing, and demographical characteristics were entered first in stepwise blocks. This was done to control their confounding influence before entering disease duration, and to be able to compare their 
Table 1 Functional disability in two groups of patients with rheumatoid arthritis

\begin{tabular}{|c|c|c|c|c|c|c|c|c|c|}
\hline & \multicolumn{4}{|c|}{ Disease duration $<1$ year $(n=97)$} & \multicolumn{4}{|c|}{ Disease duration $\geqslant 1$ year $(n=100)$} & \multirow[t]{2}{*}{ p Value } \\
\hline & $\%$ & Mean & $S D$ & Median & $\%$ & Mean & $S D$ & Median & \\
\hline $\begin{array}{ll}\text { Number of devices } & 0 \\
1\end{array}$ & $\begin{array}{l}66 \\
20\end{array}$ & & & & $\begin{array}{l}30 \\
21\end{array}$ & & & & \\
\hline$>1$ & 14 & & & & 49 & & & & $<0.01^{\star}$ \\
\hline $\begin{array}{ll}\text { Assisted activities } & 0 \\
& 1\end{array}$ & $\begin{array}{l}42 \\
23\end{array}$ & & & & $\begin{array}{l}32 \\
25\end{array}$ & & & & \\
\hline$>1$ & 35 & & & & 43 & & & & $0.32 t$ \\
\hline Overall disability score (range $0-3$ ) & & $1 \cdot 18$ & $0 \cdot 79$ & $1 \cdot 00$ & & $1 \cdot 10$ & 0.73 & $1 \cdot 13$ & $0.49 \ddagger$ \\
\hline Integrated overall disability score 5 (range $0-3$ ) & & $1 \cdot 27$ & $0 \cdot 79$ & $1 \cdot 13$ & & 1.33 & 0.73 & $1 \cdot 31$ & $0 \cdot 60 \ddagger$ \\
\hline
\end{tabular}

${ }^{\star} \chi^{2}=33 \cdot 23,2 \mathrm{df} ; \dagger \chi^{2}=2 \cdot 31,2 \mathrm{df} ; \neq \mathrm{p}$ Value from Student's $t$ test; Integrated with use of devices or assistance (see 'Methods' section).

relative contribution to explaining the variance of the disability parameters. The number of devices, number of assisted activities, and disease duration were categorised into ordinal variables for this analysis. All analyses were done with the SPSS-PC+ statistical package.

\section{Results}

FUNCTIONAL STATUS

Table 1 shows the functional status parameters of both groups. Of the patients with RA of recent onset, $66 \%$ did not use devices; $20 \%$ used one device; and 14\% used more than one device. Patients in this group most frequently used a jar opener $(17 \%)$, raised toilet seat $(11 \%)$, long handled bathroom appliances $(10 \%)$, and devices for dressing $(5 \%)$. In the group with established disease the use of devices was much more common: $30 \%$ did not use any device, $21 \%$ used one device, and almost half of the patients used more than one device. A jar opener (43\%), raised toilet seat $(33 \%)$, special taps $(33 \%)$, and long handled bathroom appliances (25\%) were most frequently used. The number of devices appeared to increase gradually in the group with established disease: patients with a disease duration of 1-7 years used on average 1.5 devices, patients with a disease duration of 8-13 years used on average $2 \cdot 2$, and patients with a disease duration of more than 13 years used 2.8 devices on average. Differences in the number of activities for which assistance from other people was required were comparable although less pronounced. The overall self report disability score, however, was about equal in both groups. The overall disability score integrating use of devices and assistance was also quite similar in both groups.
DISEASE CHARACTERISTICS AND

PSYCHOLOGICAL STATUS

Table 2 shows the disease activity and psychological wellbeing characteristics. The group with a disease duration of less than one year had significantly more inflammatory activity. This group also appeared to have a lower level of psychological wellbeing.

\section{CORRELATION BETWEEN DISABILITY}

PARAMETERS

For the correlation and regression analysis, the group with established disease and a random sample of 40 patients from the group with recent onset RA were combined. Table 3 gives Pearson's correlation coefficients for the combined group $(n=140)$. The overall disability score correlated only moderately strongly with the use of devices $(r=0 \cdot 37)$. Disability integrated with the use of devices and assistance was obviously related more strongly to the number of devices $(r=0 \cdot 62)$. The correlation between both overall disability scores and the number of assisted activities was quite strong ( $r=0.65$ and 0.77 , respectively). The correlation between the number of devices and the number of assisted activities was $0 \cdot 45$. The correlation between both overall disability scores was high $(r=0.91)$.

\section{MULTIVARIATE REGRESSION ANALYSIS}

Hierarchical multivariate regression analysis was performed to obtain an insight into the relative contribution of disease activity, psychological wellbeing, demographical variables, and disease duration in explaining variances of the disability parameters. Disease duration was divided into four categories: less

Table 2 Disease characteristics of the two groups of patients with rheumatoid arthritis

\begin{tabular}{|c|c|c|c|c|c|c|c|}
\hline & \multicolumn{3}{|c|}{ Disease duration $<1$ year $(n=97)$} & \multicolumn{3}{|c|}{ Disease duration $\geqslant 1$ year $(n=100)$} & \multirow[t]{2}{*}{ p Value ${ }^{\star}$} \\
\hline & Mean & $S D$ & Median & Mean & $S D$ & Median & \\
\hline $\begin{array}{l}\text { Disease activity (range) } \\
\text { Joint score }(0-534) \dagger \\
\text { Pain }(6-25) \ddagger \\
\text { Morning stiffness }(\mathrm{min})(0-720) \dagger \\
\text { ESR }(\mathrm{mm} / 1 \mathrm{st} h) \dagger \\
\text { Haemoglobin }(\mathrm{g} / \mathrm{l}) \\
\text { Platelets }\left(\times 10^{\circ} / \mathrm{h}\right) \dagger\end{array}$ & $\begin{array}{r}141 \\
18 \\
97 \\
38 \\
129 \\
331\end{array}$ & $\begin{array}{r}107 \\
5 \\
147 \\
28 \\
16 \\
111\end{array}$ & $\begin{array}{r}122 \\
18 \\
60 \\
29 \\
130 \\
315\end{array}$ & $\begin{array}{r}122 \\
17 \\
44 \\
30 \\
135 \\
289\end{array}$ & $\begin{array}{r}122 \\
4 \\
46 \\
25 \\
14 \\
89\end{array}$ & $\begin{array}{r}79 \\
17 \\
30 \\
25 \\
135 \\
262\end{array}$ & $\begin{array}{r}<0.01 \\
0.20 \\
<0.01 \\
0.02 \\
0.05 \\
<0.01\end{array}$ \\
\hline $\begin{array}{l}\text { Psychological wellbeing (range) } \ddagger \\
\text { Depressive mood }(0-24) \dagger \\
\text { Cheerful mood }(0-24) \\
\text { Anxiety }(10-40) \dagger\end{array}$ & $\begin{array}{r}6 \\
10 \\
21\end{array}$ & $\begin{array}{l}5 \\
5 \\
7\end{array}$ & $\begin{array}{r}5 \\
10 \\
19\end{array}$ & $\begin{array}{r}4 \\
11 \\
19\end{array}$ & $\begin{array}{l}5 \\
5 \\
5\end{array}$ & $\begin{array}{r}2 \\
11 \\
19\end{array}$ & $\begin{array}{r}<0.01 \\
0.06 \\
0.15\end{array}$ \\
\hline
\end{tabular}

${ }^{\star} \mathrm{p}$ Value from Student's $t$ test; †Values transformed to square roots for $t$ test because of skewness of the distributions; $¥$ Highe scores indicate more impact. 
Table 3 Correlation between disability parameters of 140 patients with rheumatoid arthritis*

\begin{tabular}{llll}
\hline & Devices† & Assisted activities $\dagger$ & Integrated overall disability $\neq$ \\
\hline Overall disability score & 0.37 & 0.65 & 0.91 \\
Integrated overall disability score $\neq$ & 0.62 & 0.77 & - \\
Assisted activities† & 0.45 & - & - \\
\hline
\end{tabular}

*Pearson's correlation coefficients: all probabilities $<0.01$; †Categorised in 0,1 , and $>1$ $\ddagger$ Integrated with use of devices or assistance (see 'Methods' section).

than 1 year $(n=40), 1-7$ years $(n=26), 8-13$ years $(n=31)$, and more than 13 years $(n=43)$. The four parameters of disability were the dependent variables. All independent variables from table 2 were entered in the analysis, but table 4 only gives figures on the independent variables significantly contributing $(p<0.05)$ to the variance of any of the disability parameters. The independent variables were entered in the following sets in a stepwise procedure: clinical disease activity, laboratory variables, psychological wellbeing, demographic variables and, finally, disease duration. Accordingly, table 4 shows the additional influence of disease duration on the disability variables-that is, after disease activity, psychological wellbeing, and demographics have been taken into account.

Of the $43 \%$ variance explained in case of the overall disability score, the larger part $(32 \%)$ was explained by disease activity parameters, and the psychological wellbeing variable anxiety added $9 \%$. Age and gender did not contribute significantly, and disease duration added only $2 \%$. The disability score that is integrated with the use of devices and assistance was explained for $41 \%$ : disease duration contributed only $1 \%$ after the other variables had been taken into account. The variance in number of devices used was explained for $38 \%$, of which $14 \%$ was accounted for by variables representing disease activity. Psychological wellbeing, age, and gender were not related to the use of devices in this analysis. Disease duration explained the largest part $(24 \%)$ of the variance in the number of devices. The number of activities for which assistance is needed could be explained for only $19 \%$ by all the variables entered, and had no strong relation with either of them. It is obvious that the overall disability score is relatively strongly related to disease activity and psychological wellbeing, whereas the number of devices used is much more strongly related to duration of the disease.

Altering the disease duration categories to 'less than 1 year' and 'more than 1 year', or entering disease duration as a continuous variable slightly altered the parameters of the regression models, but did not affect the main differences found in the original analysis (data not shown). Upgrading the disability score by taking a score of three instead of a score of at least two in case devices or assistance are used, also does not affect the model for the integrated overall disability score.

\section{Discussion}

In this study the use of devices or assistance in performing daily life activities appeared to be quite different between a group of patients with RA of recent onset and a group with established disease. This difference cannot be explained by the argument that patients with $\mathrm{RA}$ of recent onset have not had the opportunity to acquire the devices because of the short disease duration, because the number of devices gradually increases across four duration categories. This finding contrasts sharply with the comparable overall self report scores of disability. The use of devices correlated only moderately strongly with the disability scores. Multivariate regression analysis showed self report scores predominantly to reflect current disease activity, whereas the number of devices was more strongly related to disease duration. Disability scores and the use of devices thus appear to represent distinct dimensions of physical function in RA. Disability scores may be reflecting mainly the degree of difficulty in performing daily life activities, which is related predominantly to current disease activity and psychological wellbeing, whereas the use of devices reflects the loss of independence that gradually occurs during the course of the disease.

Table 4 Multivariate regression analysis of functional disability on disease activity, psychological wellbeing, demographical variables, and disease duration in 140 patients with rheumatoid arthritis

\begin{tabular}{|c|c|c|c|c|c|c|c|c|}
\hline & \multicolumn{2}{|c|}{ Overall disability score } & \multicolumn{2}{|c|}{ Integrated overall disability score ${ }^{*}$} & \multicolumn{2}{|c|}{ Devicest } & \multicolumn{2}{|c|}{ Assisted activitiest } \\
\hline & $\beta$ & $\delta R^{2}$ & $\beta$ & $\delta R^{2}$ & $\beta$ & $\delta R^{2}$ & $\beta$ & $\delta R^{2}$ \\
\hline $\begin{array}{l}\text { Clinical variables } \\
\text { Joint score } \neq\end{array}$ & $0 \cdot 40$ & $0 \cdot 26$ & $0 \cdot 37$ & $0 \cdot 25$ & $0 \cdot 26$ & 0.07 & $0 \cdot 20$ & 0.07 \\
\hline $\begin{array}{l}\text { Laboratory variables } \\
\text { Haemoglobin } \\
\text { Platelets } \ddagger\end{array}$ & $-0 \cdot 30$ & 0.06 & $-0 \cdot 33$ & 0.07 & $\begin{array}{l}-0 \cdot 29 \\
-0 \cdot 15\end{array}$ & $\begin{array}{l}0.04 \\
0.03\end{array}$ & & \\
\hline $\begin{array}{l}\text { Psychological wellbeing } \\
\text { Cheerful mood } \\
\text { Anxiety }\end{array}$ & $0 \cdot 31$ & 0.09 & $0 \cdot 27$ & 0.07 & & & $-0 \cdot 19$ & 0.04 \\
\hline $\begin{array}{l}\text { Demographic variables } \\
\text { Female gender } \\
\text { Age }\end{array}$ & & & $0 \cdot 40$ & 0.01 & & & $\begin{array}{l}0 \cdot 25 \\
0 \cdot 15\end{array}$ & $\begin{array}{l}0.04 \\
0.02\end{array}$ \\
\hline Disease duration $\$$ & 0.06 & 0.02 & $0 \cdot 13$ & 0.01 & 0.50 & $0 \cdot 24$ & $0 \cdot 17$ & 0.02 \\
\hline Total $R^{2}$ & & 0.43 & & 0.41 & & $0 \cdot 38$ & & $0 \cdot 19$ \\
\hline
\end{tabular}

All variables from table 2 were entered as independent variables, but only figures of significantly contributing variables are given. $\beta=$ standardised regression coefficient All variables from table 2 were entered as independent variables, but only figures of significantly contributing variables are given. $\beta=$ standardised regression coefficien
(after entering all independent variables into the model); $\delta R^{2}=$ additional variance explained over and above the variance explained by previously entered variables. (after entering all independent variables into the model); $\delta R^{2}=$ additional variance explained over and above the variance explained by previously entered variables.
$\star$ `Integrated with use of devices or assistance (see 'Methods' section); + Categories: $0=0,1=1$, and $2=>1$; $\ddagger$ Values transformed to square roots; $\lceil$ Categories: $0=<1$ ^Integrated with use of devices or assistance (see 'Me
year, $1=1-7$ years, $2=8-13$ years, and $3=>13$ years. 
Integrating the use of devices or assistance in a self report score of functional status, as is done in the HAQ disability index, hardly affects the dominance of disease activity and the lack of disease duration in explaining the disability score. Upgrading the component scales to three instead of two did not alter this finding. It can be concluded, therefore, that this practice of incorporating the use of devices or assistance in a disability score does not alter the measurement properties of the disability score. It is still mainly a measure of current disease activity, and not of increasing dependence on devices or assistance.

As this is a cross sectional study, selection bias may be present. Selection processes are a problem for any study comparing groups with various disease durations. ${ }^{19} \mathrm{~A}$ follow up study could provide more definite information, but is a costly and lengthy method to evaluate the validity of an outcome parameter. The relatively small difference in age in both groups is an indication that some selection might have taken place. The mean age in the group with disease of recent onset may be relatively high, and the mean age in the group with established disease may be relatively low. As mean ages in patient groups with comparable disease duration vary widely in published reports, neither of these possibilities can be ruled out. Whereas all patients with a newly diagnosed RA who fulfilled the entrance criteria were eligible to participate, irrespective of the subsequent course of their disease, the group who had had RA longer are more likely to be a selection of patients. As patients in the latter group actively volunteered to take part in a study on behavioural and occupational treatment modalities, patients with extremely bad developing disease as well as patients with mild disease are less likely to be part of this group. Where selection is likely to happen in two directions, important bias of the main results of this study is not to be expected.

The results of this study show self report scores of disability to be relatively strongly related to current inflammatory activity. This association appeared to be slightly stronger in the group with established disease, when both groups were analysed separately $(r=0.50$ and $0 \cdot 60$, respectively). Another factor that might explain the lack of a relation between self report scores of functional status and disease duration could be that functional capacity scores are affected by the changing way in which patients regard their own functional capacity at different stages of the disease. The association between psychological wellbeing and self report scores of disability appeared to be quite similar in both duration groups in this study (data not shown), but the effects of personality traits and coping behaviour, which were not assessed in this study, have been described in several reports. ${ }^{25} 26$ It is also possible that a degree of over-capacity in patients with RA of recent onset prevents self report scores from deteriorating. In disability questionnaires people are asked whether they can walk without help, not whether they can run. The sensitivity of the disability score is probably not sufficient to measure differences in this range of disability.

The use of devices is obviously more strongly related to disease duration, and may reflect to a greater extent enduring damage to tissue and bones. The use of devices may also reflect the results of patient education, experience, and coping styles. An increasing dependence on auxiliary devices could furthermore reduce the degree of difficulty patients experience in performing activities of daily life and in that way conceal the deterioration in functional status over time. In cases where walking is difficult but, with a cane a patient can manage, functional capacity might be estimated to be good by the patient.

The finding from this study that self report scores of disability and the use of devices are two parameters reflecting different dimensions of physical function has not been recognised in published reports thus far. It has been shown that the frequently applied procedure of integrating the use of devices or assistance and self report scores does not yield a disability measure adequately reflecting both dimensions of function. Therefore, distinct assessment of both parameters of disability seems warranted, especially in long term studies on RA and other rheumatic diseases.

We thank C J A E Huiskes and C Cornelis for the data collection in the established disease group; $T$ Vliet Vlieland and $M$ Hazes for their useful suggestions; and the rheumatologists $\mathrm{H} \mathrm{CM}$ Haanen, E J ter Borg, Y Schenk, I van Booma-Frankfort, A H M Heurkens, D M Hofman, M J van der Veen, A A Kruize, all participants of the Arthritis Res
(Stichting Reumaonderzoek Utrecht).

(Stichting Reumaonderzoek Utrecht).
This study was funded by the Dutch League against This study was funded by the
Rheumatism (Nationaal Reumafonds).

1 Fries J F, Spitz P, Kraines R G, Holman H R. Measurement of patient outcome in arthritis. Arthritis Rheum 1980; 23: $137-45$.

2 Meenan R F, Gertman P M, Mason J M. Measuring health status in arthritis: the Arthritis Impact Measurement Scales. Arthritis Rheum 1980; 23: 146-53.

3 Meenan R F, Mason J H, Anderson J J, Guccione A A, Kazis L E. AIMS2. The content and properties of a revised and expanded arthritis impact measurement scales health status questionnaire. Arthritis Rheum 1992; 35: $1-10$.

4 Peck J R, Smith T W, Ward J R, Milano R. Disability and depression in rheumatoid arthritis. A multi-trait, multimethod investigation. Arthritis Rheum 1989; 32: 1100-6.

5 Jacobs J W G, Oosterveld F G J, Deuxbouts N, et al. Opinions of patients with rheumatoid arthritis about their own functional capacity: how valid is it? Ann Rheum Dis 1992; 51: 765-8.

6 Sullivan F M, Eagers R C, Lynch K, Barber J H. Assessment of disability caused by rheumatic diseases in general practice. Ann Rheum Dis 1987; 46: 598-600.

7 Bijlsma J W J, Oude Heuvel C H B, Zaalberg A. Development and validation of the Dutch questionnaire capacities of daily life (VDF) for patients with rheumatoid arthritis. F Rehabil Sci 1990; 3: 71-4.

8 Pincus T, Callahan L F, Brooks R H, Fuchs H A, Olsen N J, Kaye J J. Self-report questionnaire scores in rheumatoid arthritis compared with traditional physical, radiographic and laboratory measures. Ann Intern Med 1989; 110: 259-66.

9 Bijlsma J W J, Huiskes C J A E, Kraaimaat F W, Veen M J van der, Huber-Bruning $O$. Relation between patients' own health assessment and clinical and laboratory findings in rheumatoid arthritis. $\mathcal{F}$ Rheumatol 1991; 18: 650-3

10 Huiskes C J A E, Kraaimaat F W, Bijlsma J W J. Development of a self-report questionnaire to assess the impact of rheumatic diseases on health and lifestyle. f Rehabil Sci 1990; 3: 65-70.

11 Meenan R F. New approaches to outcome assessment: the AIMS questionnaire for arthritis. Arch Intern Med 1986; 31: $167-85$.

12 Taal E, Jacobs J W, Seydel E R, Wiegman O, Rasker J J. Evaluation of the Dutch Arthritis Impact Measurement Scales (DUTCH-AIMS) in patients with rheumatoid arthritis. Br $\mathcal{F}$ Rheumatol 1989; 28: 487-91. 
13 Heide A van der, Jacobs J W G, Dinant H J, Bijlsma J W J. The impact of endpoint measures in rheumatoid arthritis clinical trials. Semin Arthritis Rheum 1992; 21: 287-94.

14 Hagglund K J, Haley W E, Reveille J D, Alarcón G S. Predicting individual differences in pain and functional impairment among patients with rheumatoid arthritis. Arthritis Rheum 1989; 32: 851-8.

15 Regan-Smith M G, O'Connor G T, Kwoh C K, Brown L A, Olmstead E M, Burnett J B. Lack of correlation between the Steinbrocker staging of hand radiographs and the functional health status of individuals with
rheumatoid arthritis. Arthritis Rheum 1989;32:128-33.

16 Pincus $T$, Callahan $L$ F, Sale W G, Brooks A L, Payne L E, Vaughn W K. Severe functional declines, work disability, and increased mortality in seventy-five rheumatoid arthritis patients studied over nine years. Arthritis Rheum 1984; 27: 864-72.

17 Wolfe F, Cathey M A. The assessment and prediction of functional disability in rheumatoid arthritis. $\mathcal{f}$ Rheumatol 1991; 18: 1298-306.

18 Raspe $\mathrm{H} \mathrm{H}$. Social and emotional problems in early rheumatoid arthritis 75 patients followed up for two years. Clin Rheumatol 1987; 6: 20-6.

19 Meenan R F, Kazis L E, Anthony J M, Wallin B A. The clinical and health status of patients with recent-onset clinical and health status of patients with recent-onset
20 Pincus T, Summey J A, Soraci S A, Walston K A, Mummins N P. Assessment of patient satisfaction in activities of daily life using a modified Stanford Health Assessmen Questionnaire. Arthritis Rheum 1983; 26: 1346-53.

21 Arnett F C, Edworthy S M, Bloch D A, et al. The American Rheumatism Association 1987 revised criteria for the classification of rheumatoid arthritis. Arthritis Rheum 1988; 31: 315-24.

22 Huiskes C J A E, Kraaimaat F W, Brons M R, Bijlsma $\mathrm{J}$ W J. Behavioral therapy, occupational therapy and the combination of bor in 0 ccupational therapy and the combination of both in the treatment of rheumatoid

23 Thompson P W, Silman A J, Kirwan J R, Currey H L F. Articular indices for joint inflammation with rheumatoid arthritis. Correlation with the acute-phase response. Arthritis Rheum 1987; 30: 618-23.

24 Ploeg H M van der, Defares P B, Spielberger C D. Handleiding bij de ZelfBeoordelings Vragenlijst $\mathrm{Z}$ B V. Amsterdam: Swets and Zeitlinger B V, 1980.

25 Spiegel J S, Leake B, Spiegel T M, et al. What are we measuring? An examination of self-reported functional status measures. Arthritis Rheum 1988; 31: 721-8.

26 Lorish C D. Abraham N, Austin J, Bradley L A, Alarcón G S. Disease and psychosocial factors related to physical G S. Disease and psychosocial factors related to physical 1150-7.

J 